Research Article

\title{
An Investigation of Time-Dependent Deformation Characteristics of Soft Dredger Fill
}

\author{
Wanying Wang $\mathbb{D},{ }^{1}$ Qingzi Luo $\mathbb{D},{ }^{1}$ Bingxiang Yuan $\mathbb{D}^{1},{ }^{1}$ and Xiaoping Chen $\mathbb{D}^{2}$ \\ ${ }^{1}$ School of Civil and Transportation Engineering, Guangdong University of Technology, Guangzhou 510006, China \\ ${ }^{2}$ School of Mechanics and Construction Engineering, Jinan Univerisity, Guangzhou 510632, China \\ Correspondence should be addressed to Qingzi Luo; lqz1986@gdut.edu.cn
}

Received 17 April 2020; Revised 1 June 2020; Accepted 5 June 2020; Published 8 July 2020

Academic Editor: Yanlin Zhao

Copyright (C) 2020 Wanying Wang et al. This is an open access article distributed under the Creative Commons Attribution License, which permits unrestricted use, distribution, and reproduction in any medium, provided the original work is properly cited.

\begin{abstract}
The creep characteristics of soft clays have been studied for decades. However, the lateral deformation of soils is not allowed during the commonly used one-dimensional consolidation tests, which cannot describe the real deformation features of soils in practice. On the other hand, the influence of drainage distance on the mechanical properties of soil is still controversial, classified as hypothesis $A$ and hypothesis $B$. For a better understanding of deformation characteristics of soft clay, especially which in longterms, a series of conventional oedometer tests as well as novel geometric confined consolidation tests was conducted on soft dredger fill. The results show that the secondary consolidation coefficient of the soil sample $C_{\alpha}$ would increase firstly, followed by a small decrease with the increase of consolidation pressure generally. $C_{\alpha}$ would decrease with the consolidation time and also be reduced by preloading. The strain at the completion of primary consolidation would increase with the drainage distance, but the $C_{\alpha}$ would be affected little. Both compression index $C_{c}$ and $C_{\alpha}$ of soft clay would reduce after preconsolidation, in which two parameters show an approximate linear relationship. The creep coefficient of soft clay under the geometric confinement $C_{\alpha \varepsilon}^{k}$ is larger than that under the oedometer test $C_{\alpha \varepsilon}$. However, the trends of the relationship between the creep coefficient and loading are consistent regardless of the confinement conditions.
\end{abstract}

\section{Introduction}

Soft clay could be widely found in nature, which has high water content, low permeability, high compressibility, and high viscosity. Such features could result in an excessive deformation, especially for a long period for constructions on soft clay. The deformation of soft clay has a time effect involving both consolidation and creep, which interact with each other and contribute to long-term deformation. Oedometer tests have been widely used to characterize the deformation of soft clay in long-term, which is closely related to mineral composition, magnitude of load, loading rate, temperature, water content, stress history, etc. $[1-10]$.

Due to the different conditions such as sedimentary environment, mineral composition, and stress history, the physical characteristics and mechanical behaviour of soft clay in different regions would vary a lot. For example, secondary consolidation coefficient $C_{\alpha}$ for soft clay in different regions might increase $[11,12]$, remain the same $[13,14]$, or increase first then decrease $[5,6,15-17]$ with increasing of loading. When the soil state changes from overconsolidated to normally consolidated, $C_{\alpha}$ would increase firstly followed by a decreasing with the increasing of load. The upper load corresponding to the maximum $C_{\alpha}$ may appear near the preconsolidation pressure $[6,18]$ or equal to 1.5 to 4 times the preconsolidation pressure [15-17]. When the soil is in the normal consolidation state, $C_{\alpha}$ would not change with the consolidation pressure anymore [14]. $C_{\alpha}$ is also closely related to the loading ratio. When the loading ratio decreases, $C_{\alpha}$ would decrease due to the quasi-overconsolidation phenomenon caused by creep $[16,19,20]$. Mesri [21] revealed a positive correlation between $C_{\alpha}$ and compression index $C_{c}$ for several typical soft clays. Subsequently, Santagate et al. [22] and Jesmani et al. [4] also reached the consistent conclusion in their studies. 
Mainstream theories to explain whether the creep effect occurs after the excess pore water pressure has dissipated or it already begins at the primary consolidation stage were classified into Hypothesis $A$ and Hypothesis $B$, according to Ladd et al. [23]. The scholars supporting Hypothesis $A$ [24-29] believe that the creep deformation occurs after the completion of primary consolidation. For the same soil mass, the strain value at the completion of primary consolidation is unique and independent of thickness of soil sample or drainage boundary conditions. Mesri and Choi [26] conducted a series of oedometer tests under different drainage conditions, and they agreed that creep existed in the primary consolidation stage. However, they proposed that the relationship between the end-of-primary (E-O-P) void ratio and effective vertical stress of soil samples with different thicknesses was still unique due to the interaction between consolidation effects and creep effects in the primary consolidation stage, which was a proof of the Hypothesis $A$. In Hypothesis $B$, creep deformation has occurred in the primary consolidation stage. For the same kind of soil, the strain value at the completion of primary consolidation is related to the thickness of soil sample as well as the drainage boundary conditions, e.g., more creep deformation occurs in the primary consolidation stage if the distance of drainage path is larger. The majority of laboratory as well as in situ test results support the Hypothesis $B$ [30-36]. For the contradiction of the two hypotheses, Kabbaj et al. [35] pointed out that the soil sample used in tests for Mesri and Choi [26] was obtained by using a soil collector with a diameter of $50 \mathrm{~mm}$. In this case, the soil sample was disturbed significantly, which could lead to an underestimate of the practical settlement prediction by laboratory test results. However, an agreement is not being reached on this issue yet.

For a better understanding of deformation characteristics for soft clay, especially for that in long term, this study conducted a series of one-dimensional confined consolidation tests on soft clay in the eastern Shantou City of China, including the conventional oedometer tests and novel geometric confined consolidation tests, which could simulate the real deformation characteristics of soft clay in practice. During the improved geometric confined consolidation tests, vertical and limited lateral deformations of soil would occur at the same time. Thus, the deformation parameters considering the influence of lateral deformation could be obtained. Based on the test results, the effect of loading magnitude, preloading, loading time, thickness of soil sample, and lateral constraint conditions on the longterm deformation of soft clay was systematically studied and discussed.

\section{Materials, Apparatus, and Testing Procedure}

The soil tested in this study is soft dredger fill, which is taken from the eastern economic zone in Shantou City, Guangdong Province, PRC (Figure 1). A thin-walled soil sampler with a height of $50 \mathrm{~cm}$ and a diameter of $10 \mathrm{~cm}$ was used to obtain the undisturbed soil samples at a distance of 7.0 to $9.0 \mathrm{~m}$ below the ground, which was below the groundwater level (Figure 2). The sampling and transportation procedures

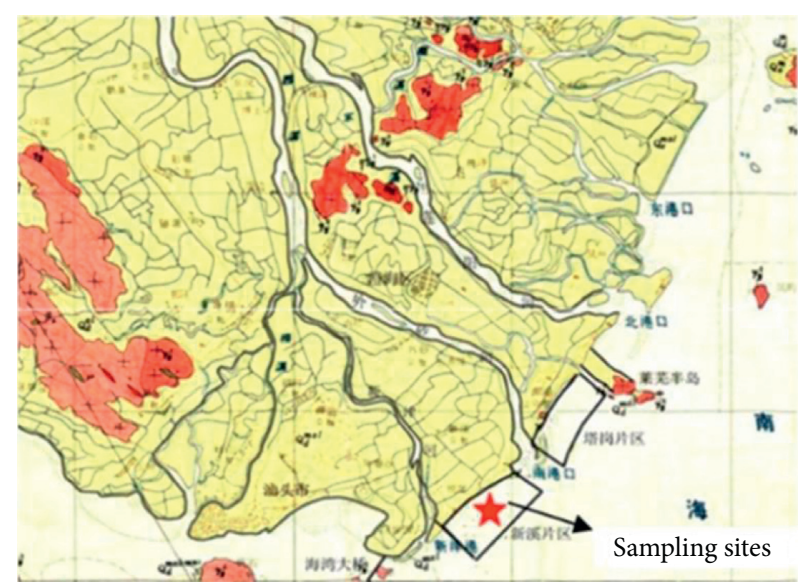

Figure 1: The sampling sites in Shantou city, China.

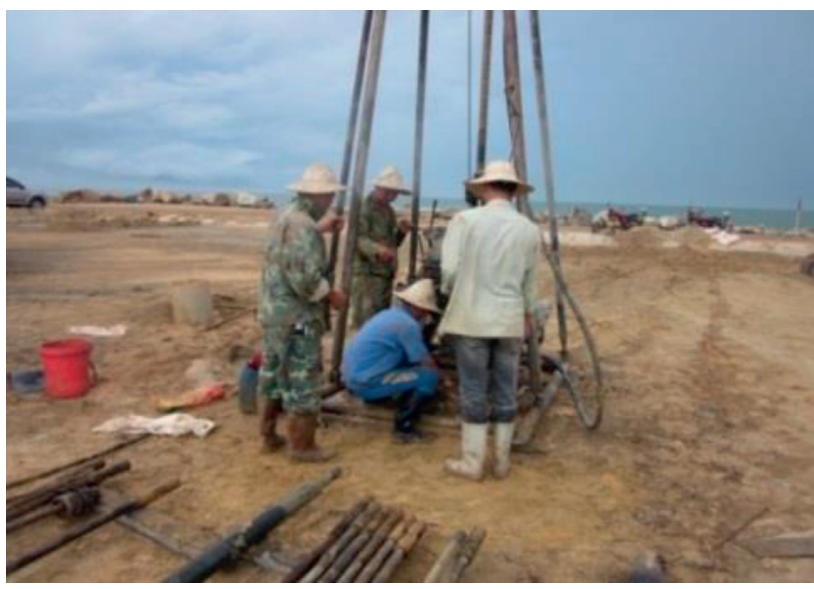

FIgURE 2: The image of the sampling process.

were carefully done to avoid any disturbance to the intact soil samples $[37,38]$. The soil samples were muddy soft clay with grey-black colour. It could be found that the soft clay was mixed with a small amount of fine sand or chips of shells locally, which should be removed from soil samples in order to ensure the accuracy and uniformity of test results [39, 40]. The results of particle size analysis showed that the content of clay $(d<5 \mu \mathrm{m})$ accounted for about $37.4 \%$, the content of cement $(d<2 \mu \mathrm{m})$ accounted for about $18.7 \%$, the content of sand particles $(d>75 \mu \mathrm{m})$ was about $14 \%$, and the content of organic matter was approximately $4 \%$. The physical properties of the soil samples are shown in Table 1. The soil samples were saturated with a high initial void ratio and water content. According to the Casagrande method, the preconsolidation pressures of the samples are 48 to $53 \mathrm{kPa}$, while the overburden pressure is about $160 \mathrm{kPa}$, so that the soil is in an unconsolidated state [41].

A series of oedometer tests was conducted on soil samples with a same area of $30 \mathrm{~cm}^{2}$ and thickness of $2 \mathrm{~cm}$, $4 \mathrm{~cm}, 6 \mathrm{~cm}$, and $10 \mathrm{~cm}$, respectively. The samples with double-drainage boundaries were tested in a constant temperature of $24 \pm 1^{\circ} \mathrm{C}$ to avoid the scatters of test results caused by temperature change. Details of all the oedometer tests under step loading are summarized in Table 2. It is 
TABLE 1: The physical properties of soft clay used in this study.

\begin{tabular}{lcccccccc}
\hline Sample depth $(\mathrm{m})$ & $w(\%)$ & $\rho\left(\mathrm{g} / \mathrm{cm}^{3}\right)$ & $d_{s}$ & $e_{0}$ & $S_{r}(\%)$ & $w_{L}(\%)$ & $w_{p}(\%)$ & $p_{c}(\mathrm{kPa})$ \\
\hline $7.0-9.0$ & $39-57$ & $1.72-1.79$ & $2.62-2.65$ & $1.05-1.67$ & $95.4-100$ & $34.5-36.5$ & $17.9-22$ & $48-53$ \\
\hline
\end{tabular}

$w$ : water content; $\rho$ : bulk density; $d_{s}$; specific gravity; $e_{0}$ : initial void ratio; $S_{r}$ : degree of saturation; $w_{L}$ : liquid limit; $w_{p}$ : plastic limit; $p_{c}$ : preconsolidation pressure.

TABLE 2: Summary of consolidation tests conducted in this study.

\begin{tabular}{|c|c|c|c|c|c|c|}
\hline Test & Soil sample & No. & $e_{0}$ & $\begin{array}{l}\text { Thickness } \\
(\mathrm{cm})\end{array}$ & $\begin{array}{l}\text { Consolidation time } \\
\text { (d) }\end{array}$ & Loading step $(\mathrm{kPa})$ \\
\hline \multirow{12}{*}{ Oedometer test } & Undisturbed & 1 & 1.63 & 4 & 6 & $25-50-100-200-400-800-1600$ \\
\hline & Undisturbed & $2^{*}$ & 1.16 & 2 & 1 & $25-50-100-200-400-800$ \\
\hline & Undisturbed & 3 & 1.15 & 2 & 1 & $25-50-100-200-400-800$ \\
\hline & Undisturbed & 4 & 1.14 & 2 & 1 & $25-50-100-200-400-800$ \\
\hline & Undisturbed & 5 & 1.16 & 2 & 2 & $25-50-100-200-400-800$ \\
\hline & Undisturbed & 6 & 1.17 & 2 & 3 & $25-50-100-200-400-800-1600$ \\
\hline & Remoulded & $7^{\#}$ & 1.34 & 2 & 2 & $50-100-200-400-800$ \\
\hline & Remoulded & $8^{\#}$ & 1.34 & 4 & 3 & $50-100-200-400-800$ \\
\hline & Remoulded & $9^{\#}$ & 1.34 & 6 & 5 & $50-100-200-400-800$ \\
\hline & Remoulded & $10^{\#}$ & 1.34 & 10 & 8 & $50-100-200-400-800$ \\
\hline & Undisturbed & 11 & 1.67 & 4 & 6 & $50-100-200-400-800$ \\
\hline & Remoulded & 12 & 1.42 & 4 & 4 & $25-50-100-200-400-800$ \\
\hline \multirow{2}{*}{$\begin{array}{l}\text { Geometric confined consolidation } \\
\text { test }\end{array}$} & Undisturbed & 13 & 1.67 & 4 & 6 & $\begin{array}{l}\text { Axial: } 50-100-200-400-800 \\
\text { Lateral: } 30-60-120-240-480\end{array}$ \\
\hline & Remoulded & 14 & 1.42 & 4 & 4 & $\begin{array}{l}\text { Axial: } 25-50-100-200-400-800 \\
\text { Lateral: } 15-30-60-120-240-480\end{array}$ \\
\hline
\end{tabular}

*Tests with a preloading of $100 \mathrm{kPa} .{ }^{\#}$ Tests with a preloading of $25 \mathrm{kPa}$.

noted that, for test no. 2 , the soil sample was firstly preloaded for 3 days under $100 \mathrm{kPa}$ to investigate the effect of preloading on the mechanical behaviour of the sample. Besides, preloading of $25 \mathrm{kPa}$ was also applied on test no.7-no.10 for two days to avoid the scatter caused by the sampling procedure of remoulded samples. After the preloading was removed and rebounding completed, the step loading listed in Table 2 was performed on the soil samples.

Another kind of test conducted in this study was the geometric confined consolidation test using an improved GJY $K_{0}$ consolidation apparatus made by Nanjing Soil Instrument, PRC (Figure 3). For the improved apparatus, the soil sample was separated from the pressure chamber by a rubber membrane with a thickness of $3 \mathrm{~mm}$. Meanwhile, the pressure chamber was filled with deaired water and connected with the confining pressure controlling system to obtain a constant lateral confining pressure. Mechanical behaviour of soil sample, which has a thickness of $4 \mathrm{~cm}$ and an area of $30 \mathrm{~cm}^{3}$ with double-drainage boundaries, was studied during step loading. In this case, a parameter $K^{*}$ named "geometric confined coefficient" was proposed, which was defined as $K^{*}=\sigma_{3} / \sigma_{1}$, where $\sigma_{1}$ is the vertical stress and $\sigma_{3}$ is the confining pressure. $K^{*}$ remained a constant throughout the test, e.g., 0.6, smaller than the earth pressure coefficient at rest $K_{0}$, i.e., $0.74 \sim 0.78$, to allow a certain lateral deformation of soil sample under loading. The temperature during the tests was consistent with that for oedometer tests as $24 \pm 1^{\circ} \mathrm{C}$. The axial displacement and lateral pressure are recorded by a dial gauge and load cells, respectively. The details of the two geometric confined consolidation tests are listed in Table 2.

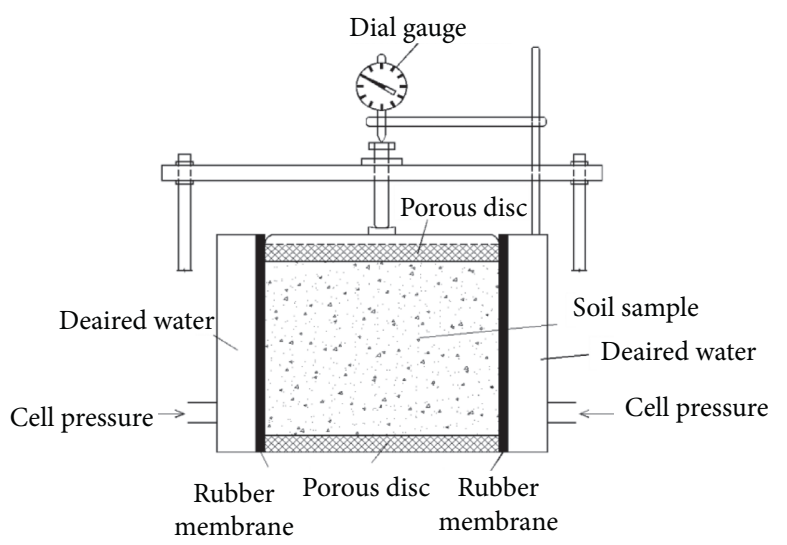

FIGURE 3: The improved apparatus for geometric confined consolidation tests.

\section{Results and Discussion}

The Casagrande method is commonly used to distinguish primary consolidation and secondary consolidation for onedimensional consolidation tests (Figure 4). In this method, the slope of the $e-\log t$ curve for secondary consolidation is considered as the value of $C_{\alpha}$. According to Leroueil et al. [42] and Mesri and Godlewski [43], the values of the $C_{\alpha}$ would decrease with time. However, $C_{\alpha}$ could remain constant at least in the first two logarithmic cycles. Therefore, in order to avoid the influence of different logarithmic cycles on the determination of $C_{\alpha}$, the first logarithmic cycle after the completion of primary consolidation was selected 


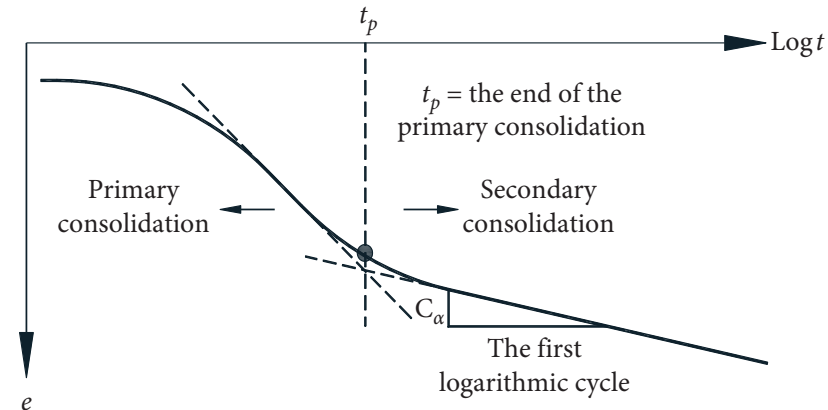

FIGURE 4: Diagram of the division of the primary consolidation and the secondary consolidation.

to determine $C_{\alpha}$ in this study. The equation to obtain $C_{\alpha}$ is as follows:

$$
C_{\alpha}=\frac{-\left(e_{2}-e_{1}\right)}{\left(\lg t_{2}-\lg t_{1}\right)}
$$

where $t_{1}$ is the time when the primary consolidation completed, $t_{2}$ is the time when the first logarithmic cycle completed, and $e_{1}$ and $e_{2}$ are the void ratios of the soil sample at $t_{1}$ and $t_{2}$, respectively.

In oedometer tests, lateral deformation of soil sample is not allowed and the area of the soil sample remains constant. Therefore, the void ratio $e$ could be simply derived from vertical cumulative strain. If equation (1) is described in terms of vertical strain $\varepsilon$, a parameter named creep coefficient for one-dimensional consolidation $C_{\alpha \varepsilon}$ is proposed:

$$
C_{\alpha \varepsilon}=\frac{\left(\varepsilon_{2}-\varepsilon_{1}\right)}{\left(\lg t_{2}-\lg t_{1}\right)},
$$

where $t_{1}$ is the time when the primary consolidation completed for one-dimensional consolidation, $t_{2}$ is the time when the first logarithmic cycle completed for one-dimensional consolidation, and $\varepsilon_{1}, \varepsilon_{2}$ are the vertical cumulative strains at $t_{1}$ and $t_{2}$, respectively.

In geometric confined consolidation tests (e.g., test nos. 13 and 14), the lateral constraint of soil sample is flexible, which allows a certain lateral deformation of soil samples. In this case, the area of soil sample has been increasing and void ratio is difficult to measure or calculated from vertical strain. Therefore, the secondary consolidation coefficient $C_{\alpha}$ is difficult to be obtained and equation (1) is invalid. The creep coefficient for geometric confined consolidation $C_{\alpha \varepsilon}^{k}$ is introduced, which is derived from the vertical strain as follows:

$$
C_{\alpha \varepsilon}^{k}=\frac{\left(\varepsilon_{2}^{k}-\varepsilon_{1}^{k}\right)}{\left(\lg t_{2}^{k}-\lg t_{1}^{k}\right)}
$$

where $t_{1}^{k}$ is the time when the primary consolidation completed for geometric confined consolidation, $t_{2}^{k}$ is the time when the first logarithmic cycle completed for geometric confined consolidation and $\varepsilon_{1}^{k}$ and $\varepsilon_{2}^{k}$ are the vertical cumulative strains at $t_{1}^{k}$ and $t_{2}^{k}$, respectively. The introduction of creep coefficients $C_{\alpha \varepsilon}$ and $C_{\alpha \varepsilon}^{k}$ makes the creep properties of soil samples under different lateral constraint more comparable.
Figure 5 shows the relationship between the void ratio $e$ and lg $t$ for oedometer test no. 6 . It could be observed that when the consolidation pressure is small, e.g., less than $50 \mathrm{kPa}$, the soil sample is in the overconsolidation state so that the inflection point on the $e-\lg t$ curve is not obvious and the value of $C_{\alpha}$ is small. As the consolidation pressure gradually increases, the soil sample turns to normal consolidation state and the vertical deformation of the sample would increase significantly. In this case, the $e-\lg t$ curve shows a reverse " $S$ " and an obvious inflection point occurs. Moreover, the slope of $e-\lg t$ curve in the secondary consolidation stage has little change with the load in the normal consolidation state.

Chen's method $[44,45]$ was used to analyze the results of soil samples under the step-loading, in order to obtain the deformation-time curves under a single-loading and then the isochronous curves of stress-strain relationship (Figure 6). It could be observed that the stress-strain relationships of soil samples are a series of curves with a same trend and the deformation of the soil exhibits a nonlinear characteristic. However, when the upper load is small (less than $63 \mathrm{kPa}$ ) indicating the soil is in the overconsolidated state, the stress-strain relationship of the soil sample is approximately linear. With the increase of the load, the soil turns to the normal consolidation stage and the stress-strain relationship curves of the soil samples are deflected to the stress axis and present significant nonlinear characteristics.

\subsection{Relationship between Secondary Consolidation} Coefficient and Loading for Oedometer Tests. In this study, for test nos. 1, 11, 13, and 14, the value of $C_{\alpha}$ increases first and then slightly decreases with the increasing of loading. It could reach a maximum value when the consolidation pressure is about $\eta \cdot p_{c}\left(\eta \approx 3.2-3.5 ; p_{c}\right.$ is the preconsolidation pressure), as shown in Figure 7(a), taking test no. 1 as an example. For the other oedometer tests, e.g., test no. $4, C_{\alpha}$ would increase continually with the consolidation pressure increasing and the slope of the $C_{\alpha}-p$ curve is related to the preconsolidation pressure $p_{c}$ (Figure $7(\mathrm{~b})$ ). It could be seen that when the loading is less than $\eta \cdot p_{c}(\eta \approx 2.3), C_{\alpha}$ increased dramatically with the load increasing. Whereas when the loading exceeds $\eta \cdot p_{c}(\eta \approx 2.3)$, the rise of $C_{\alpha}$ would decline.

Figure 7 shows that the inflection point of $C_{\alpha}-p$ curve does not occur near the preconsolidation pressure $p_{c}$ but the value of $\eta \cdot p_{c}$ does. This result is consistent with the previous research such as [15] and [46], in which the value of $\eta$ was about 1.5 to 3.5. However, Chen et al. [3] proposed that the inflection point of $C_{a}-p$ curve would occur near $p_{c}$ based on their test results. The reasons for this contradiction need to be further studied, but it might be attributed to the quasioverconsolidation due to the loading time being longer than the primary consolidation completion time or the load increment ratio.

According to the mechanism of the variation of $C_{a}$ with the consolidation pressure, the $C_{a}-p$ curves in Figure 7 could be divided into three stages. In stage I $\left(p<p_{c}\right)$, the soil is in the overconsolidated state. The soil structure formed during natural deposition would restrict the development of 


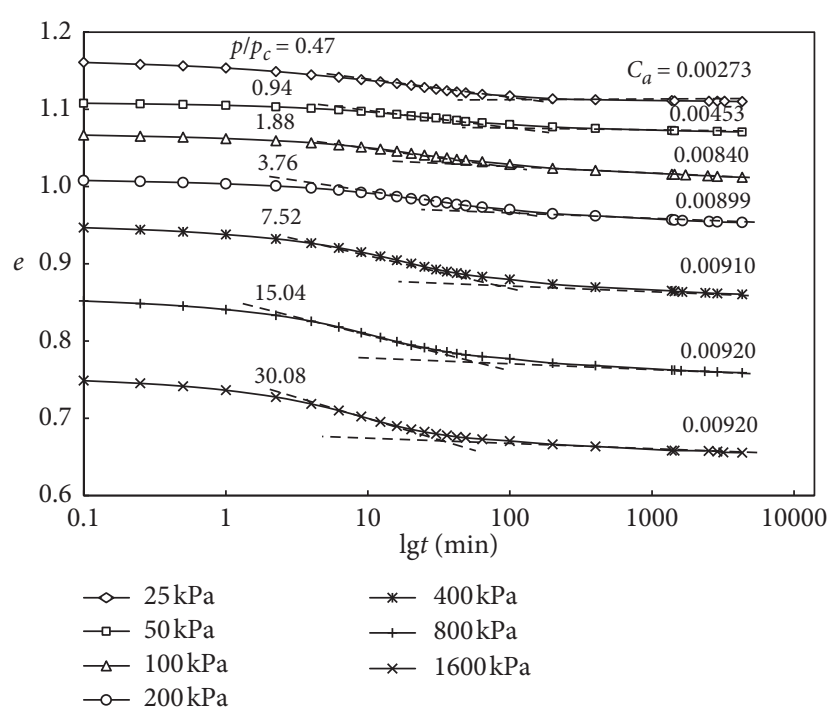

FIGURE 5: $e-\lg t$ curves under different consolidation pressures for the oedometer test (test no. 6).

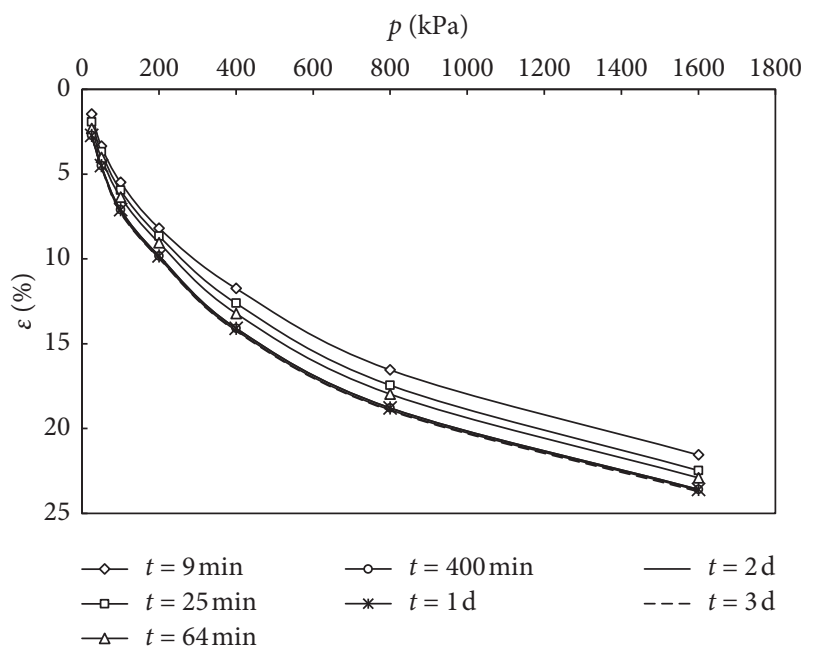

FIGURE 6: Isochronous curves of stress-strain relationship for test no. 6 .

secondary consolidation. In this case, the rearrangement of soil particles and the creep deformation of the bound water would be restricted so that the value of $C_{\alpha}$ is small. Based on Bjerrum's theory of equitime $e$ - $\lg p$ curve, Yin et al. [19] developed a method to calculate the secondary consolidation deformation of overconsolidated soils $\Delta e_{s}$ as follows:

$$
\Delta e_{s}=C_{\alpha} \cdot \lg \left(\frac{t_{1}+\Delta t}{t_{i}}\right),
$$

where $\Delta t$ is the time increment, and the equivalent creep time $t_{i}$ can be calculated by

$$
t_{i}=t_{c} \cdot \lg \left(\frac{p_{c}}{p_{i}}\right)^{C_{c}-C_{\alpha} / C_{\alpha}},
$$

where $t_{c}$ is the time when the primary consolidation completed, $p_{c}$ is the preconsolidation pressure, $p_{i}$ is the

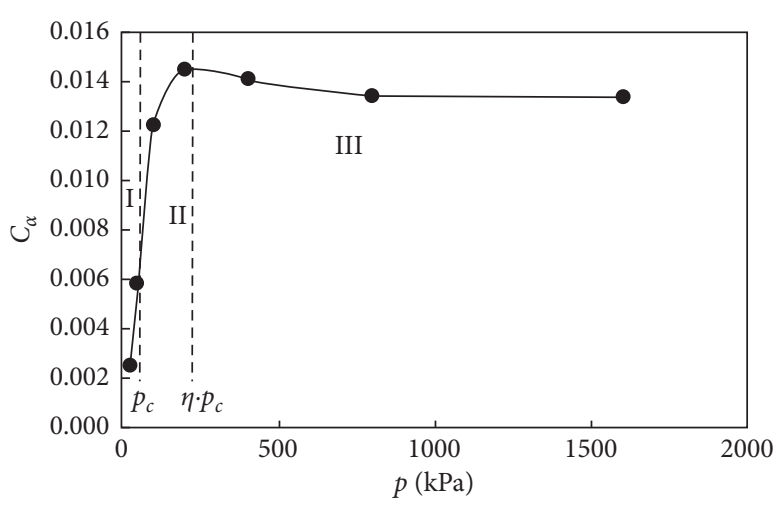

(a)

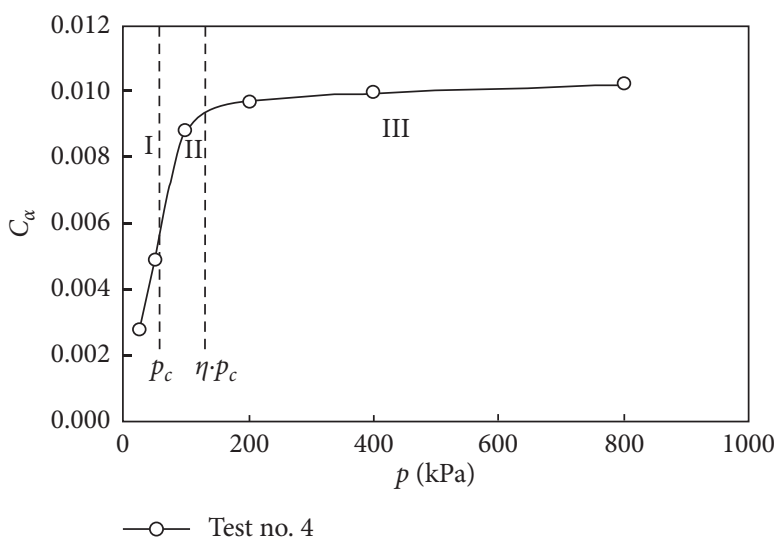

(b)

FIgURE 7: The relationship between the secondary consolidation coefficient and the consolidation pressure for (a) test no. 1 and (b) test no. 4 .

pressure after loading, which is less than $p_{c}$, and $C_{c}$ is the compression index.

It can be found that the secondary consolidation deformation in the overconsolidation stage is related to the consolidation pressure. When the consolidation pressure increases to $p_{c}$, the $C_{\alpha}-p$ curve would turn into stage II, in which the cementations between the soil particles are gradually destroyed with the loading increasing. Then, soil particles would be rearranged along the force direction to their new equilibrium positions. Meanwhile, the intermolecular force between bound water and particles would decrease, leading to an increase of the secondary consolidation effect. However, when the load continues to increase to exceed $\eta \cdot p_{c}$, the structures between soil particles and between bound water and particles could be destroyed completely, resulting in a decrease of the volume of voids inside the soil. The soil sample approaches to the remoulded state, and the increment of secondary consolidation deformation of the sample declines with the load and tends to be stable gradually, which is defined as stage III. For test nos. 1 and 11 , due to their relatively high water content and macrovoid ratio, the intermolecular forces between soil particles and between the bound water and particles would decease dramatically. Therefore, the rearrangement of soil 
particles in stage II is more remarkable and the secondary consolidation effect is more obvious, leading to a longer stage II and a larger $C_{\alpha}$ even compared with that for stage III. In test nos. 13 and 14, a certain lateral deformation was allowed due to the flexible lateral confinement during the test, resulting in more rearrangements of soil particles along with a longer stage II.

3.2. Effect of Preloading on Secondary Consolidation Coefficient. For test no. 2, the soil sample was preloaded for 3 days under $100 \mathrm{kPa}$ and then unloaded. The step loading in a sequence of $25 \mathrm{kPa}-50 \mathrm{kPa}-100 \mathrm{kPa}-200 \mathrm{kPa}-400 \mathrm{kPa}-800$ $\mathrm{kPa}$ would not be performed on the soil sample until the rebounding displacement did not change any more. Figure 8 illustrates that the relationship between $C_{\alpha}$ and $p$ for test no. 2 compared with that for the soil sample without preloading (test no. 3).

It could be concluded that $C_{\alpha}$ of soil sample after preloading tends to be smaller than that for soil sample without preloading under the same consolidation pressure, whereas the reduction differs under the different loading levels. For example, under the load of $100 \mathrm{kPa}, C_{\alpha}$ for the sample after preloading reduces by nearly $50.9 \%$ compared with that for the sample without preloading, while this reduction is only $3.84 \%$ under $800 \mathrm{kPa}$. The effect of preloading on $C_{\alpha}$ increases first and then decreases with the increasing of the consolidation pressure. It could be observed from Figure 8 that when consolidation pressure is $100 \mathrm{kPa}$, the preloading has the greatest impact on the secondary consolidation effect. The above results could be explained by theory of equitime $e-\lg p$ curve. If $p<100 \mathrm{kPa}$, the soil without preloading was in the overconsolidation state. The value of $C_{\alpha}$ was small, and the preloading did not change the consolidation state of the soil sample. Therefore, the change of the secondary consolidation effect caused by the preloading is not remarkable, e.g., from point $A$ to point $B$ in Figure 9 (point $B$ is on the rebound recompression curve). If the soil sample was preloaded for 3 days under $100 \mathrm{kPa}$, the deformation of the soil would creep from point $C$ to point $D$, and it would rebound along a straight line $l$ when unloaded. When it was reloaded again, the yield point of sample would then develop to point $E$. It is noted that the preconsolidation pressure $p_{v}$ at point $E$ was greater than preloading of $100 \mathrm{kPa}$, resulting in a quasi-overconsolidation of the soil sample. For a soil sample without preloading, it was in a normal consolidation state under a load of $100 \mathrm{kPa}$. While after preloading, the consolidation state of the soil changed to overconsolidation state due to quasi-overconsolidation phenomenon caused by the creep effect under the load of $100 \mathrm{kPa}$. The difference of consolidation state of the soil sample caused by preloading leads to a notable variation of $C_{\alpha}$. When the consolidation pressure was greater than $p_{v}$, the soil samples were in a normal consolidation state no matter with or without preloading. As the consolidation pressure increased, the relationship between $e$ and $p$ would develop along the normal consolidation line (line $t_{c}$ ) as shown in Figure 9. In this situation, it could be considered

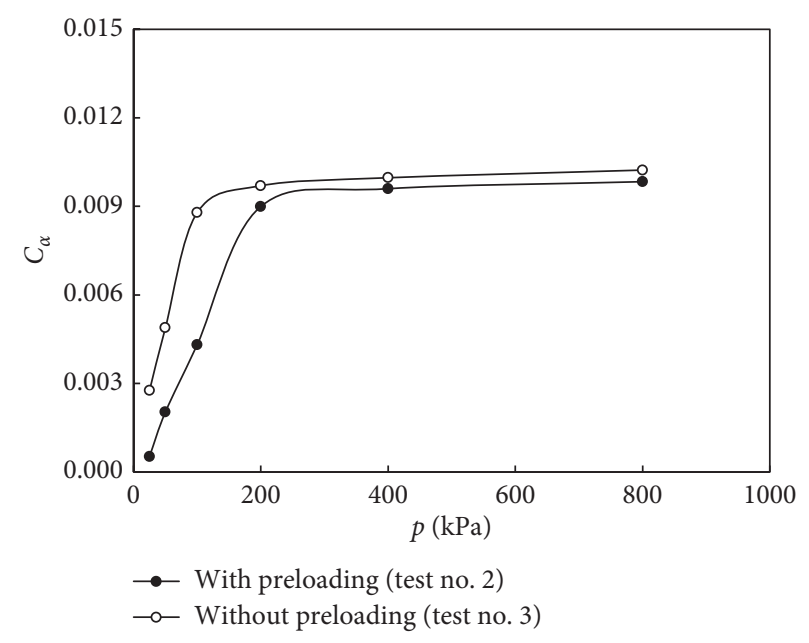

FIgURE 8: The effect of preloading on the relationship between the secondary consolidation coefficient and the consolidation pressures.

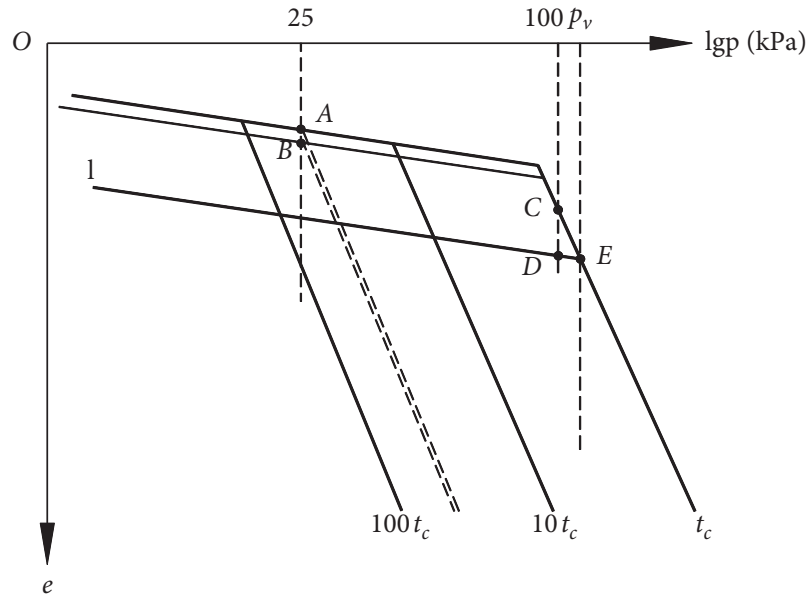

Figure 9: Bjerrum's equitime $e-\lg p$ curve.

that the decrease of the initial void ratio of the soil sample after the preloading is the reason of the decrease of $C_{\alpha}$.

The results also show that the reduction of the compression index $C_{c}$ of soil sample caused by preloading at the step loading of $100 \mathrm{kPa}$ was about $79.2 \%$, which was about 1.5 times of the reduction of $C_{\alpha}$ under the same condition. In practice, preloading is commonly used for soft clay in foundation treatment. This study could explain the reasonability and effectiveness of this method from the mechanism and confirmed that preloading could prevent more deformations of primary consolidation under the same loading as the prepressure.

\subsection{Variation of Secondary Consolidation Coefficient with} Consolidation Time. For test nos. 4, 5, and 6, soil samples were consolidated for 1 day, 2 days, and 3 days, respectively. The values of $C_{\alpha}$ under different consolidation pressures as well as different consolidation time periods are listed in Table 3. It could be seen from Table 3 that the consolidation time cannot 
TABLE 3: The list of secondary consolidation coefficients for different consolidation time periods and different consolidation pressures.

\begin{tabular}{lcccccc}
\hline Consolidation time $(\mathrm{d})$ & \multicolumn{5}{c}{ Consolidation pressure (kPa) } \\
& 25 & 50 & 100 & 200 & 400 \\
\hline 1 & 0.00276 & 0.00489 & 0.00879 & 0.00970 & 0.00997 & 0.01023 \\
2 & 0.00276 & 0.00473 & 0.00857 & 0.00941 & 0.00952 & 0.00970 \\
3 & 0.00273 & 0.00453 & 0.00840 & 0.00897 & 0.00910 & 0.00920 \\
\hline
\end{tabular}

affect the trend of the variation of $C_{\alpha}$ with the consolidation pressure. However, $C_{\alpha}$ would decrease slightly with the increasing of consolidation time under the same consolidation pressure and the effect of consolidation time on $C_{\alpha}$ would increase with the increasing of the consolidation pressure. The longer the consolidation time, the larger the creep deformation and the smaller the void ratio of soil sample, resulting in a decreasing of the value of $C_{\alpha}$. As mentioned above, the value of $C_{\alpha}$ for soil sample in overconsolidated state is smaller than that for soil sample in the normal consolidated state. The step loading was conducted in this study so that the impact of the consolidation time on $C_{\alpha}$ would be accumulated. Therefore, the reduction of $C_{\alpha}$ for soil sample consolidated for 3 days compared with that for 1 day under $800 \mathrm{kPa}$ is about 2.8 times of the reduction under $50 \mathrm{kPa}$.

\subsection{Effect of Drainage Distance on Secondary Consolidation} Coefficient. In order to study the influence of drainage distance on $C_{\alpha}$, a series of oedometer tests were conducted on soil samples with different thicknesses of $2 \mathrm{~cm}, 4 \mathrm{~cm}$, $6 \mathrm{~cm}$, and $10 \mathrm{~cm}$ (no. 7 to no. 10 soil samples, respectively). The samples were remoulded soils, and the test results were analyzed using Chen's method. Figure 10 shows the $\varepsilon-\lg t$ curves of soil samples with different thicknesses under a load of $100 \mathrm{kPa}$. It can be found that, with the decrease of the thickness of the sample, $\varepsilon-\lg t$ curve tends to move downward, despite of coincidence of curves during the secondary consolidation state. Meanwhile, the strain at the completion of primary consolidation $\varepsilon_{\mathrm{EOP}}$ would also decrease with the decrease of the thickness of the sample, i.e., $7.15 \%, 6.6 \%, 6.25 \%$, and $5.75 \%$ for the thickness of $10 \mathrm{~cm}$, $6 \mathrm{~cm}, 4 \mathrm{~cm}$, and $2 \mathrm{~cm}$, respectively. The deformation characteristics are consistent with Hypothesis $B$ [23], in which the creep already occurs in the primary consolidation state. The strain at the completion of primary consolidation would vary with the thickness of the soil sample, i.e., the strain would decrease with the decreasing of the thickness of the sample. This is because the thinner the soil sample, the shorter completion time of the primary consolidation and the less creep deformation during the primary consolidation. This study has further confirmed that the E-O-P curve of the soil is related to the thickness of the soil sample. Therefore, if the deformation parameters obtained from the laboratory tests would be used in the assessment of the settlement in practice, the effect of thickness of soil layers should be taken into consideration.

Figure 11 shows the relationship between $C_{\alpha}$ and the thickness of the soil sample under different consolidation pressure conditions. It is noted that $C_{\alpha}$ for soil samples with different thicknesses changed little under the same

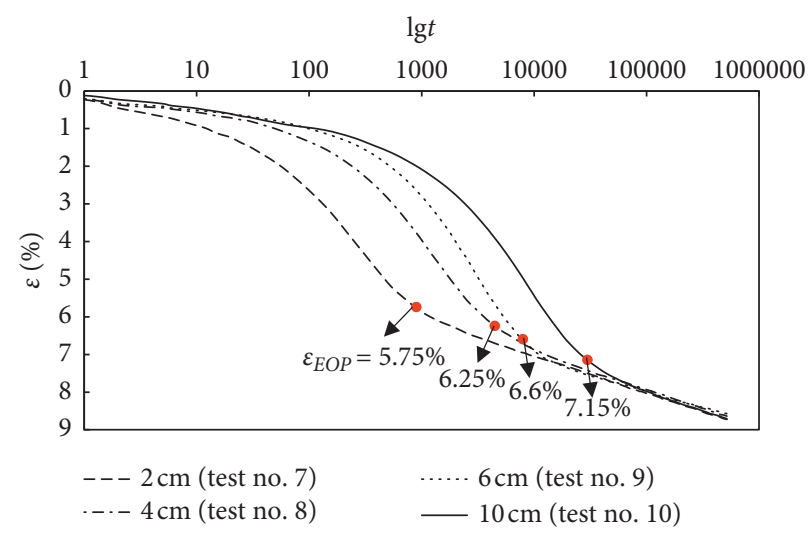

FIGURE 10: $\varepsilon-\lg t$ curves for soil samples with different thicknesses under the step loading of $100 \mathrm{kPa}$ of the oedometer tests.

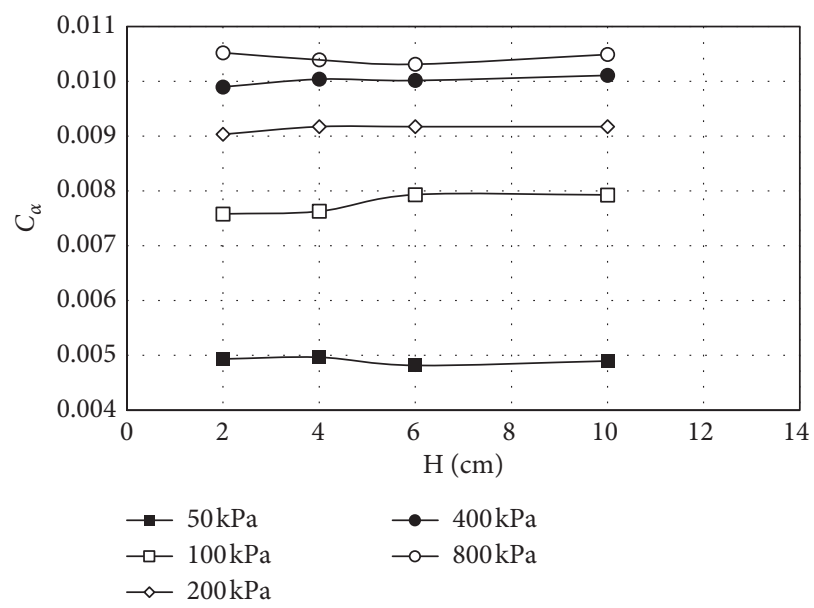

FIGURE 11: The relationship between the secondary consolidation coefficient and the thickness of soil samples under different loading steps.

consolidation pressure. This is because, although the strain of the thick soil sample is larger at the completion of the primary consolidation, the primary consolidation time is also longer. According to equation (3), the effect of thickness of soil samples on the value of $C_{\alpha}$ is slightly under the same loading step.

3.5. Effect of Confinement on the Creep Coefficient. As previously described, the creep coefficients of soil samples in one-dimensional consolidation as well as in geometric confined consolidation could be obtained from equations (2) 
and (3), respectively. For oedometer tests, the relationship between the creep coefficients $C_{\alpha \varepsilon}$ and the secondary consolidation coefficient $C_{\alpha}$ is shown as follows:

$$
C_{\alpha \varepsilon}=\frac{C_{\alpha}}{\left(1+e_{0}\right)}
$$

where $e_{0}$ is the initial void ratio of the soil sample.

Figure 12 illustrates the relationship between the creep coefficient and consolidation loading for both undisturbed soil samples and remoulded soil samples under different confinements (specimens used in test nos. 11 and 13 were undisturbed soil while those in test nos. 12 and 14 were remoulded soil). It is noted that both the creep coefficient for oedometer tests $C_{\alpha \varepsilon}$ and that for geometric confined consolidation test $C_{\alpha \varepsilon}^{k}$ would increase firstly with the load increasing, followed by a slight decrease and then tend to be stable for undisturbed soil (Figure 12(a)). The same trend could be found for remoulded soil as shown in Figure 12(b). This is because, under geometric confinement, the lateral deformation of soil sample results in more rearrangements of soil particles and distortions of bound water inside the specimen. Besides, the creep deformation of the sample in this case concludes two parts: volume creep and shear creep. By contrast, for oedometer tests, as the lateral deformation is restricted rigidly, the creep deformation is only associated with volume creep, i.e., the secondary consolidation deformation.

In geometric confined consolidation tests, the ratio of confining pressure to the vertical load remained a constant as 0.6. Although the confinement was not rigid, there was still a constraint of lateral deformation of the specimen to a certain extent. Therefore, the volume creep still dominated the total creep while the shear creep played a secondary role and no shear creep failure occurred, so that the trend of creep coefficient with load increasing for geometric confined consolidation tests changed little compared with that in oedometer tests (Figure 10).

\subsection{Relationship between Secondary Consolidation} Coefficient and Compression Index. Walker [47] conducted a series of oedometer tests on Leda soft clay. The results indicated that the ratio of the secondary consolidation coefficient $C_{\alpha}$ to the compression index $C_{c}$ was approximately a constant about 0.025. Subsequently, Mesri and Choi [26] investigated the relationship between $C_{\alpha}$ and $C_{c}$ for 22 kinds of soft clays. They proposed that the value of $C_{\alpha} / C_{c}$ remained almost a constant for the same kind of clay. This ratio could range from 0.025 to 0.1 for different kinds of soft clays. In this study, the results of 15 oedometer tests (thickness of $2 \mathrm{~cm}$ for soil samples) were analyzed, and then the ratios of $C_{\alpha} / C_{c}$ for soft clay in the eastern Shantou City were obtained. The value of $C_{\alpha} / C_{c}$ ranges from 0.021 to 0.045 , which roughly agrees with the conclusion of Mesri and Choi [26]. Little scatters of data might contribute to experimental errors or errors during secondary consolidation analysis. The relationships between $C_{\alpha}$ and $C_{c}$ for the 15 tests were plotted in Figure 13 . The results present a linear relationship between $C_{\alpha}$ and $C_{c}$ approximately, and the average ratio of $C_{\alpha} / C_{c}$ is about 0.032 .

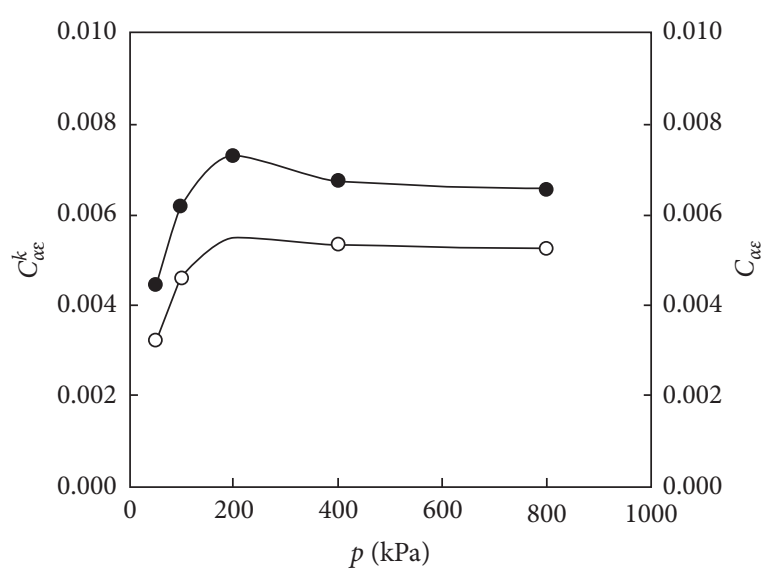

$-\quad$ Geometric confined condition (test no. 13)
$-0 \quad \mathrm{~K}_{0}$ confined condition (test no. 11)

(a)

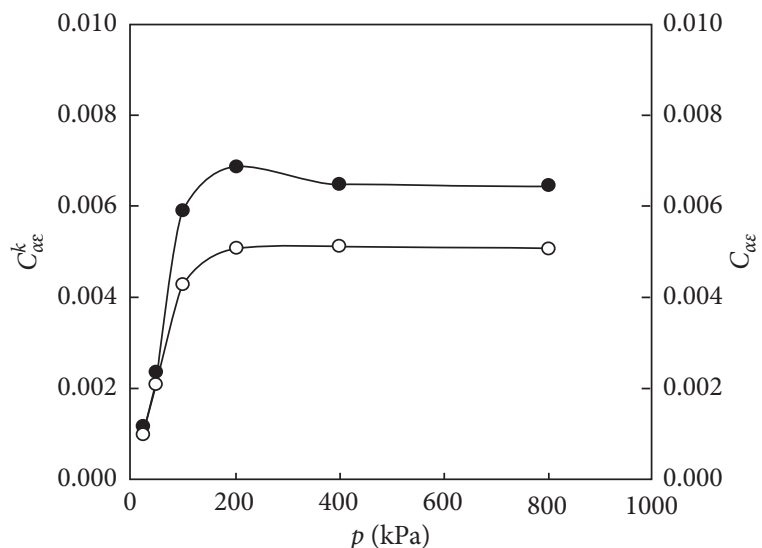

- Geometric confined condition (test no. 14)

- $\quad \mathrm{K}_{0}$ confined condition (test no. 12)

(b)

FIgURE 12: The comparison of the relationship between creep coefficients and the consolidation pressure under $K_{0}$ confinement with that under geometric confinement for (a) undisturbed soil and (b) remoulded soil.

3.7. Characteristics of Microstructure of Soil Samples after Consolidation. Compaction characteristics in terms of microstructure of soil samples after consolidation for 15 days under a load of $100 \mathrm{kPa}$ could be observed by the scanning electron microscope (SEM). Figure 14 presents the images of soil samples before and after oedometer tests (at a magnification of 1000 times and 5000 times, respectively). It could be seen from Figures 14(a) and 14(c) that there are more pores and higher void ratio inside the undisturbed soft clay. The microstructure is mainly loose flocculation structure and soil particles in a kind of slice state distributed loosely. The soil particles are aligned along the direction of gravity slightly but not markedly. In this case, the interconnections between soil particles are mostly edge-to-edge or edge-to-surface contacts, for which the cementations are weak. By contrast, the images of soil samples with different magnifications after 


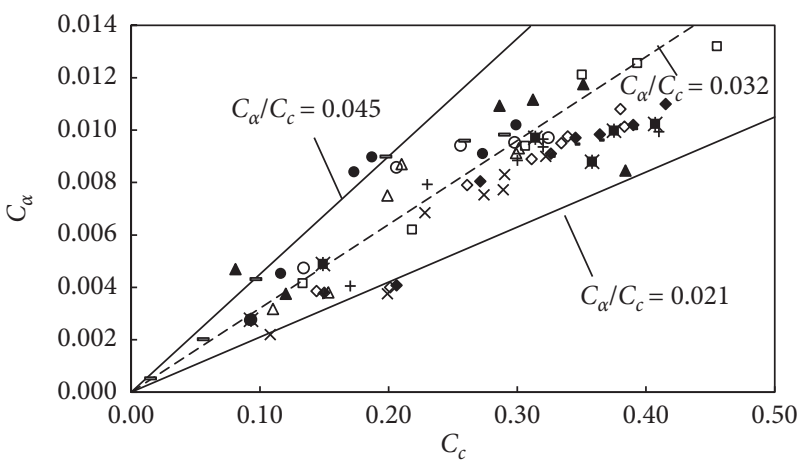

Figure 13: The relationship between the secondary consolidation coefficient and the compression index for oedometer tests.

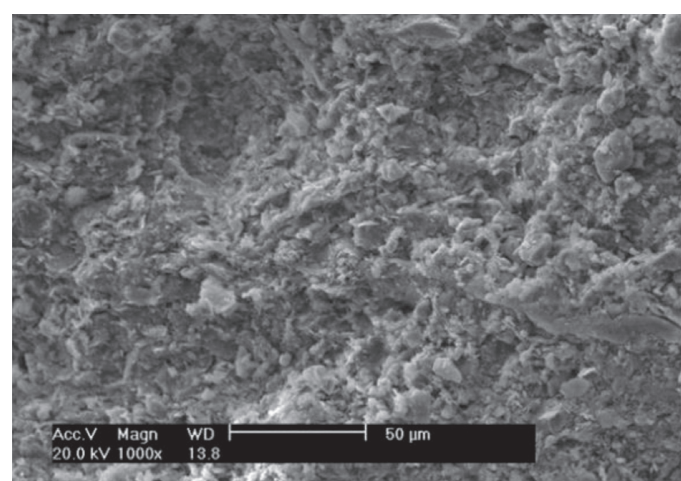

(a)

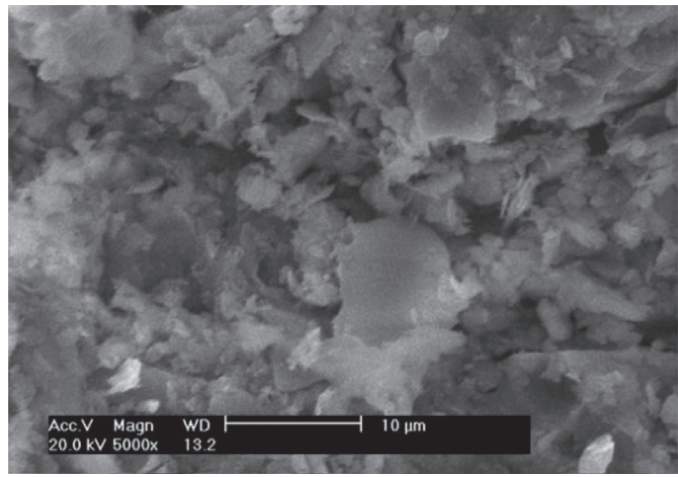

(c)

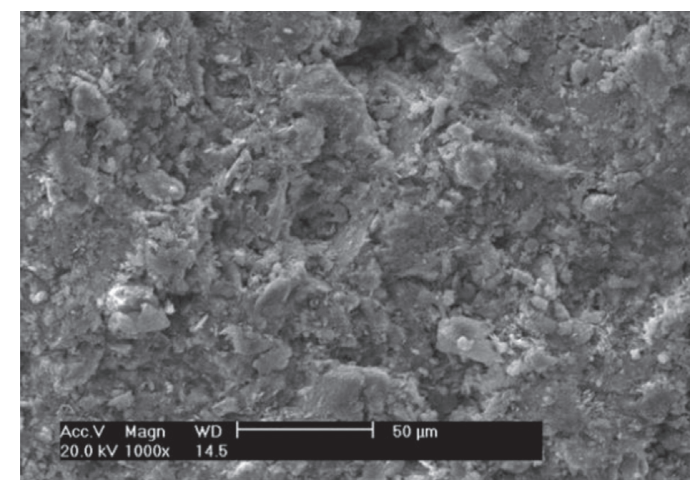

(b)

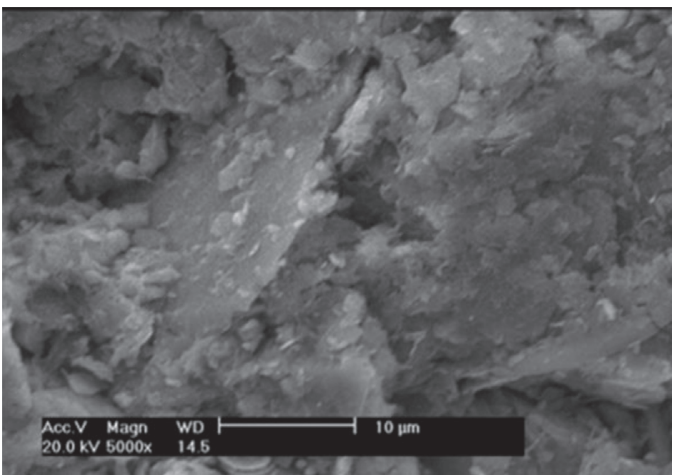

(d)

FIGURE 14: The SEM images for (a) undisturbed soil with a magnification of 1000 times; (b) soil samples after the oedometer test with a magnification of 1000 times; (c) undisturbed soil with a magnification of 5000 times; and (d) soil samples after oedometer tests with a magnification of 5000 times.

consolidation (Figures $14(\mathrm{~b})$ and $14(\mathrm{~d})$ ) show a compact microstructure of samples, resulting in an obvious reduction of void ratio in terms of macroscopic scales. The soil particles rearrange in the direction perpendicular to the consolidation pressure to be more close and even overlap with each other. The connection between particles turns to surface-to-surface contact and the microstructure of the soil sample tends to be a stable clot-like structure.

\section{Conclusions}

In this study, a series of oedometer tests and geometric confined consolidation tests were conducted on soft clay samples in eastern Shantou City, China. The deformation characteristics of consolidation, especially in long-term consolidation, were systematically investigated for soft clay. The results could be concluded as follows:

(1) Generally, the secondary consolidation coefficient $C_{\alpha}$ of the soft clay would continuously increase with the load increasing, although the increment could reduce gradually. However, $C_{\alpha}$ would increase firstly to the maximum value, followed by a decrease with the increase of the load for soil samples with a high initial void ratio. A turning point occurs at the point where the loading approaches to 1.5-3.5 times the preconsolidation pressure. 
(2) Both compression index and secondary consolidation coefficient of soft clay would reduce after preconsolidation while the reductions could be different under different loadings. The effect of preconsolidation is more dramatic on the compression index than that on the secondary consolidation coefficient.

(3) The secondary consolidation coefficient would decrease with the increase of the consolidation time, being hardly affected by the drainage distance.

(4) The creep coefficient of soft clay under the geometric confinement is larger than that under the oedometer test. However, the trends of the relationship between the creep coefficient and loading are consistent regardless of the confinement conditions. The main reason is that, although shear creep occurs during geometric confined consolidation, the majority of creep deformation is still caused by the volumetric creep, which contributes to the entire creep deformation of soil samples in one-dimensional consolidation.

(5) An approximate linear correlation can be observed between the secondary consolidation coefficient and compression index. The value of $C_{\alpha} / C_{c}$ ranging from 0.021 to 0.045 falls roughly within the variation range proposed by Mesri and Choi [26].

\section{Data Availability}

The data used to support the findings of this study are included within the article.

\section{Conflicts of Interest}

The authors declare that there are no conflicts of interest regarding the publication of this paper.

\section{Acknowledgments}

This work was supported by the National Natural Science Foundation of China (Grant nos. 51809050, 41902288, and 51978177) and Natural Science Foundation of Guangdong Province (Grant no. 2020A1515010811).

\section{References}

[1] B. P. Wen and X. Z. Jiang, "Effect of gravel content on creep behavior of clayed soil at residual state: implication for its role in slow-moving landslides," Landslides, vol. 2, no. 14, pp. 559-576, 2017.

[2] R. Bag and A. Rabbani, "Effect of temperature on swelling pressure and compressibility characteristics of soil," Applied Clay Science, vol. 136, pp. 1-7, 2017.

[3] X. Chen, Q. Luo, and Q. Zhou, "Time-dependent behaviour of interactive marine and terrestrial deposit clay," Geomechanics and Engineering, vol. 7, no. 3, pp. 279-295, 2014.

[4] M. Jesmani, R. Vaezi, and M. Kamalzare, "Correlation between $\mathrm{C}_{\alpha} / \mathrm{C}_{c}$ ratio and index parameters of soils," Quarterly Journal of Engineering Geology and Hydrogeology, vol. 45, no. 2, pp. 207-220, 2012.
[5] S. Kazemian, B. B. K. Huat, A. Prasad, and M. Barghchi, "A state of art review of art review of peat: geotechnical engineering perspective," International Journal of Physical Sciences, vol. 6, no. 8, pp. 1974-1981, 2011.

[6] S. Leroueil, "Compressibility of clays: fundamental and practical aspects," Journal of Geotechnical Engineering, vol. 122, no. 7, pp. 534-543, 1996.

[7] B. X. Yuan, L. Xiong, L. Zhai et al., "Transparent synthetic soil and its application in modeling of soil-structure interaction using optical system," Frontiers in Earth Science, vol. 7, p. 276, 2019.

[8] W. Li, M. R. Coop, K. Senetakis, and F. Schnaid, "The mechanics of a silt-sized gold tailing," Engineering Geology, vol. 241, no. 26, pp. 97-108, 2018.

[9] W. Li and M. R. Coop, "Mechanical behaviour of panzhihua iron tailings," Canadian Geotechnical Journal, vol. 56, no. 3, pp. 420-435, 2019.

[10] Y. X. Wang, P. P. Guo, W. X. Ren et al., "Laboratory investigation on strength characteristics of expansive soil treated with jute fiber reinforcement," International Journal of Geomechanics, vol. 17, no. 11, Article ID 04017101, 2017.

[11] Q. Z. Luo, X. Y. Wei, Q. M. Liu, and X. P. Chen, "Experimental study on secondary consolidation of soft dredger fill," China Civil Engineering Journal, vol. 48, no. 2, pp. 257-261, 2015.

[12] G. H. Shao and S. Y. Liu, "Research on secondary consolidation of structural marine clays," Rock and Soil Mechanics, vol. 29, no. 8, pp. 2067-2062, 2008.

[13] C. J. Zhang, S. H. Chen, G. Q. Liang, and H. Y. Wei, "Experimental study on the secondary consolidation properties of marine soft," Applied Mechanics and Materials, vol. 638-640, pp. 452-456, 2014.

[14] L. Bjerrum, "Embankments on softground: state of the art report," in Proceedings of Speciality Conference on Performance of Earth and Earth Supported Structures, Purdue University, Lafayette, IN, USA, June 1972.

[15] A. Madaschi and A. Gajo, "One-dimensional response of peaty soils subjected to a wide range of oedometric conditions," Géotechnique, vol. 65, no. 4, pp. 274-286, 2015.

[16] T. M. Le, B. Fatahi, and H. Khabbaz, "Viscous behaviour of soft clay and inducing factors," Geotechnical and Geological Engineering, vol. 30, no. 5, pp. 1069-1083, 2012.

[17] D. F. T. Nash, G. C. Sills, and L. R. Davison, "One-dimensional consolidation testing of soft clay from bothkennar," Géotechnique, vol. 42, no. 2, pp. 241-256, 1992.

[18] Y. Gui, Z. H. Yu, H. M. Liu, J. Cao, and Z. C. Wang, "Secondary consolidation properties and mechanism of plateau lacustrine peaty soil," Chinese Journal of Geotechnical Engineering, vol. 37, no. 8, pp. 1390-1398, 2015.

[19] Z. Z. Yin, H. B. Zhang, J. G. Zhu, and G. W. Li, "Secondary consolidation of soft soils," Chinese Journal of Geotechnical Engineering, vol. 25, no. 5, pp. 521-526, 2003.

[20] J. J. Stanley, "Pre-compression for improving foundation soil," Journal of the Geotechnical Engineering Division, vol. 96, no. 1, pp. 111-114, 1970.

[21] G. Mesri, "Primary compression and secondary compression," Geotechnical Special Publications, vol. 199, pp. 122-166, 2003.

[22] M. Santagata, A. Bobet, C. T. Johnston, and J. Hwang, "Onedimensional compression behavior of a soil with high organic matter content," Journal of Geotechnical and Geoenvironmental Engineering, vol. 134, no. 1, pp. 1-13, 2008.

[23] C. C. Ladd, R. Foott, K. Ishihara, F. Schlosser, and H. G. Poulos, "Stress-deformation and strength characteristic," in Proceedings of the 9th International Conference on Soil 
Mechanics and Foundation Engineering, Tokyo, Japan, July 1977.

[24] G. M. T. Kane, "Reassessment of isotaches compression concept and isotaches consolidation models," Journal of Geotechnical and Geoenvironmental Engineering, vol. 144, no. 3, pp. 115-127, 2018.

[25] L. L. Zeng, S. Y. Liu, and Z. S. Hong, "EOP compression characteristics of natural structural clays," Journal of Southeast University, vol. 40, no. 3, pp. 604-608, 2010.

[26] G. Mesri and Y. K. Choi, "The uniqueness of the end-ofprimary (EOP) void ratio-effective stress relationship," in Proceedings of the 11th International Conference on Soil Mechanics and Foundation Engineering, San Francisco, CA, USA, January 1985.

[27] B. X. Yuan, K. Xu, Y. X. Wang, R. Chen, and Q. Z. Luo, "Investigation of deflection of a laterally loaded pile and soil deformation using the PIV technique," International Journal of Geomechanics, vol. 17, no. 6, Article ID 04016138, 2017.

[28] Y. Zhao, L. Zhang, W. Wang, J. Tang, H. Lin, and W. Wan, "Transient pulse test and morphological analysis of single rock fractures," International Journal of Rock Mechanics and Mining Sciences, vol. 91, pp. 139-154, 2017.

[29] Y. Zhao, L. Zhang, W. Wang, C. Pu, W. Wan, and J. Tang, "Cracking and stress-strain behavior of rock-like material containing two flaws under uniaxial compression," Rock Mechanics and Rock Engineering, vol. 49, no. 7, pp. 26652687, 2016.

[30] W.-Q. Feng and J.-H. Yin, "A new simplified hypothesis b method for calculating consolidation settlements of double soil layers exhibiting creep," International Journal for $\mathrm{Nu}$ merical and Analytical Methods in Geomechanics, vol. 41, no. 6, pp. 899-917, 2017.

[31] T. M. Le, B. Fatahi, M. Disfani, and H. Khabbaz, "Analyzing consolidation data to obtain elastic viscoplastic parameters of clay," Geomechanics and Engineering, vol. 8, no. 4, pp. 559594, 2015.

[32] S. A. Dagago, G. Grimstad, H. P. Jostad, S. Nordal, and M. Olsson, "Use and misuse of isotache concept with respect to creep hypotheses a and b," Géotechnique, vol. 61, no. 10, pp. 898-908, 2011.

[33] G. Imai and Y.-X. Tang, "A constitutive equation of onedimensional consolidation derived from inter-connected tests," Soils and Foundations, vol. 32, no. 2, pp. 83-96, 1992.

[34] S. Leroueil, "Tenth Canadian geotechnical colloquium: recent developments in consolidation of natural clays," Canadian Geotechnical Journal, vol. 25, no. 1, pp. 85-107, 1988.

[35] M. Kabbaj, F. Tavenas, and S. Leroueil, "In situ and laboratory stress-strain relationships," Géotechnique, vol. 38, no. 1, pp. 83-100, 1988.

[36] T. Berre and K. Iversen, "Oedometer test with different specimen heights on a clay exhibiting large secondary compression," Géotechnique, vol. 22, no. 1, pp. 53-70, 1972.

[37] Y. L. Zhao, L. Y. Zhang, W. J Wang, W. Wan, and W. H. Ma, "Separation of elastoviscoplastic strains of rock and a nonlinear creep model," International Journal of Geomechanics, vol. 18, no. 1, Article ID 04017129, 2018.

[38] Y. X. Wang, P. P. Guo, H. Lin et al., "Numerical analysis of fiber-reinforced soils based on the equivalent additional stress concept," International Journal of Geomechanics, vol. 19, no. 11, Article ID 04019122, 2019.

[39] B. Yuan, M. Sun, L. Xiong, Q. Luo, S. P. Pradhan, and H. Li, "Investigation of 3D deformation of transparent soil around a laterally loaded pile based on a hydraulic gradient model test,"
Journal of Building Engineering, vol. 28, no. 3, Article ID 101024, 2020.

[40] Y. Zhao, Y. Wang, W. Wang, L. Tang, Q. Liu, and G. Cheng, "Modeling of rheological fracture behavior of rock cracks subjected to hydraulic pressure and far field stresses," Theoretical and Applied Fracture Mechanics, vol. 101, pp. 59-66, 2019.

[41] E. M. A. Ahmed, Code for Investigation of Geotechnical Engineering, National Standard of the People's Republic of China, Beijing, China, 2009.

[42] S. Leroueil, M. Kabbaj, F. Tavenas, and R. Bouchard, "Stressstrain-strain rate relation for the compressibility of sensitive natural clays," Géotechnique, vol. 35, no. 2, pp. 159-180, 1985.

[43] G. Mesri and P. M. Godlewski, "Time and stress-compressibility interrelationship," Journal of the Geotechnical Engineering Division, vol. 103, no. 5, pp. 417-430, 1977.

[44] T. K. Tan, "Determination of the rheological parameters and the harding coefficients of clays," in Rheology and Soil Mechanics, J. Kravtchenko and P. M. Sirieys, Eds., Springer, Berlin, Germany, pp. 265-272, 1966.

[45] T.-K. Tan and W.-F. Kang, "Locked in stresses, creep and dilatancy of rocks, and constitutive equations," Rock Mechanics Felsmechanik Mecanique des Roches, vol. 13, no. 1, pp. 5-22, 1980.

[46] B. K. Reddy, R. B. Sahu, and S. Ghosh, "Consolidation behavior of organic soil in normal Kolkata deposit," Indian Geotechnical Journal, vol. 44, no. 3, pp. 341-350, 2014.

[47] L. K. Walker, "Undrained creep in a sensitive clay," Géotechnique, vol. 19, no. 4, pp. 515-529, 1969. 